\title{
Collective Responsibility for Notetaking in Higher Education: Unanticipated Outcomes from a Pedagogical Research Project
}

\author{
Beth Pickard \\ University of South Wales, UK
}

\begin{abstract}
This pedagogical research project sought to address the challenge disabled students reported in acquiring specialist provision in the first term of university study. The time taken to establish specialist provision has historically affected students' attainment and wellbeing. This project aimed to provide an accessible technological provision to all students through an online notetaking platform. Following ethical approval, an online platform was embedded within the virtual learning environment for students to upload their notes from an undergraduate module where they received tuition in note-taking strategies. A mixedmethods Questionnaire and Focus Group evaluated the project. Findings were analysed using descriptive statistics and Thematic Analysis. There was very limited engagement with the online platform. It was assumed that the provision was inaccessible, not of interest, or not relevant. However, the qualitative data demonstrated that students had developed a commitment to sharing their notes but had chosen a social media platform over the intended academic portal. Other insightful outcomes included students' attitudes towards others and students' lack of confidence. This project emphasises the responsibility of educators to consider the accessibility of provision; nurturing awareness of others' learning and developing an inclusive course community, embedding technology-enhanced learning and social media in higher education.
\end{abstract}

\section{Introduction}

The UK Higher Education (HE) sector is currently exploring reforms to the Disabled Students' Allowances' (DSA) [1], to critical reception [2, 3]. Martin et al. [3] summarise the intentions of these activities as "embedding inclusive practice to reduce the requirement for individualised reasonable adjustments" (p. 6), transferring many responsibilities for supporting disabled students to HE institutions. Against this backdrop, the UK Government announced the removal of funding for non-specialist support workers like notetakers, proposing a shift in the culture of supporting disabled students in HE. The Department for Education [4] suggest:

\begin{abstract}
"In most cases, the expectation is that [Higher Education Providers] HEPs will offset the impact of the removal of DSAs funding by providing reasonable adjustments to disabled students as they are required to do under the Equality Act 2010. The expectation is that some of these will be anticipatory adjustments made to course delivery at a more universal level, to enable more inclusive learning, while some will still be provided on an individual basis."
\end{abstract}

While this decision initially affected England only, universities in Wales were eager to keep abreast of developments, with the Welsh Assembly Government (WAG) commissioning a review of the DSA process to understand the specific Welsh context [5].

As such, this research study sought to develop a feasible, sustainable and effective model of enabling notetaking which might continue if availability of specialist notetaking provision were to be reduced. The implementation of the proposed approach could ensure the embedding of reasonable adjustments and inclusivity at the point of delivery, ensuring the university meets student support requirements and legal obligations under Equality Act (2010) legislation and that disabled students have equitable access to education. The use of accessible technology to facilitate this project was a key consideration in its conception.

As the Quality Assurance Agency (QAA) [7] note: "Higher Education providers, staff and students all have a role in and responsibility for promoting equality" and nurturing an inclusive environment. This sentiment aligns with the researcher's belief in principles of Universal Design for Learning [8] and its centrality in inclusive higher education [3]. This project positions this responsibility for accessibility and inclusion with academic staff and innovatively with the peer group, as opposed to the disabled student or the Disability Service, through engagement with accessible and mainstream technology. It is proposed that this is an opportunity to explore and develop a social justice approach to graduate attributes and citizenship in Higher Education. Fitzwater [9] suggests that the "intentionality of a pedagogy along these lines would quite radically reshape educational institutions and 
their learning activities not just at the level of design and assessment requirements but also in terms of existential, social and political aims" (p. 131-132).

\section{Context: The Construct of Disability}

This study takes its definition of disabled students from Seale et al. [10]:

"Disabled students are presented as oppressed victims of their universities, who are deprived of equitable access to important learning resources as a result of institutional noncompliance with legal requirements, professional codes of practice or technical standards and guidelines" (p. 119).

This definition echoes the social model of disability which recognises systems, environments and attitudes as more disabling than individual differences [11]. Interestingly, WAG [6] firmly advocates this perspective and encourages this interpretation across its provision. A separate study recognises that Welsh HE primarily defines and acknowledges disability from a medicalised, deficitbased perspective, likely stemming from the DSA requirement to prove disabled identity through acquisition of medical evidence, and the Equality Act (2010)'s individual, deficit-based definition of disability.

A myriad of potential disability discourses is acknowledged from the outset, and are influential in the conception, implementation, experience and evaluation of this project. It is acknowledged that the students involved in this project may be responding to or commenting upon the conflicting discourses of disability encountered within the multitudes of systems, processes, roles and relationships in HE and the impact of this on their identity formation [12]. A further complication is the binary divide of disabled/non-disabled identification which students are "requested but not required" to provide [12] (p. 39). Identifying as disabled can be advantageous to acquiring necessary support for study [13] but can also have great connotations of stigma [14]. The literature discusses a further division between visible and invisible disabilities, and students identifying as experiencing an invisible disability may have to decide how much of a disabled identity they will choose to share $[13,15]$.

Lawson [16] suggests that the context of identifying as disabled in $\mathrm{HE}$ is different to other service providers, suggesting that universities will be expected to create "an open, welcoming and supportive atmosphere in order to encourage disclosures of disability and to invite such disclosures on an on-going basis" (p. 110). It is unclear whether this responsibility is being realised in practice, with many studies reporting the challenge of securing specialist support for disabled students in HE [5, 12, 17, 18].

\section{The UK Higher Education Environment}

The Disability Discrimination Act (2005) enshrined the prohibition of discrimination against disabled students in $\mathrm{HE}$, with the Equality Act (2010) further emphasising the responsibility to make proactive, reasonable adjustments to enable student participation on equitable grounds. Failure to comply with the requirements of the Equality Act (2010) amounts to discrimination. There is critical debate about the efficacy of the Equality Act (2010) in achieving equitable access to HE [19], and the terminology of "reasonable adjustment" and "reasonable steps" can be highly problematic when reflecting on the reproduction of nonrepresentational forms of power in HE [14]. There is also debate about whether certain approaches equate to universal design for learning [8], which is arguably best practice [3], rather than "reasonable adjustment", and whether this such "pursuit of inclusive education benefits all students, not just those with particular impairments" [19] (p. 149).

The Quality Assurance Agency [7] encourages HE Institutions "to work in partnership with students to understand the implications of their specific needs" (p. 10). The European Human Rights Commission (EHRC) also emphasises the importance of considering the disadvantage a disabled student would face if reasonable adjustments were not made, and takes an increasingly firm approach, recognising the time and effort that might be expended by a disabled student in overcoming disadvantage. Hammer, Werth and Dunn [20] discuss disabled students working doubly hard in comparison with their non-disabled peers to manage both their disability and their study. This navigation of complex systems [4,5] provides a further layer of inequity to the HE experience, that this project was eager to address.

\section{Methodology}

\subsection{Ontology, Epistemology, Methodology}

This study subscribes to an Interpretivist Ontology and a Social Constructionist epistemology, recognising that students' experience of disability and $\mathrm{HE}$ are socially constructed and thus diverse. This research project pursued a primarily qualitative methodology to capture the lived experiences of disabled and non-disabled students engaging with the online platform and tuition on notetaking. Some 
quantitative questions were included to establish usage of the platform, including metrics which the platform didn't offer the researcher. These quantitative statistics gave context to the rich qualitative findings and enabled some tangible evidence of engagement with the resource alongside the crucial understanding of students' perceptions of the project. Critical Disability Studies is also applied as a theoretical framework and methodology for conceptualising and developing this research project [11].

\subsection{Data Collection}

The project was completed during the first semester of the 2018-2019 academic year and conformed to the ethical standards of the British Educational Research Association (BERA). Following a successful application to the university's Faculty Ethics Committee, an online platform was developed where students would have the opportunity to upload notes taken during their Academic Skills lectures, following an initial taught session on notetaking strategies and skills. In advance of the project, options were explored for the most appropriate platform to engage with. Considerations included both the advantages and disadvantages of mirroring an assessment upload on the Virtual Learning Environment (VLE). Another crucial consideration was the anonymity of the upload. While a model of training and celebrating diligent notetaking of students was proposed and considered, there was concern that this could further perpetuate an emphasis on normative and ableist ways of being and doing in higher education [14, 18]. An anonymous platform was sought, but unfortunately, was not possible. Therefore, a Sharepoint site was developed and a hyperlink to this platform embedded within the VLE folders, which students were encouraged to access as part of their studies. It was hoped this would avoid mirroring anxieties of uploading an assignment through the VLE, but would also maintain and develop students' familiarity and engagement with the VLE.

An input was delivered as part of the Academic Skills module on potential models, strategies and functions of note taking, drawing from level appropriate resources as well as professional guidance for note takers. Following the input, students were invited and reminded each week about voluntarily uploading their notes to the online platform.

At the conclusion of the module, a brief mixedmethods questionnaire was circulated to generate initial evaluative commentary. This included two quantitative questions about students' usage of the platform, as well as several open, qualitative questions to explore reasoning behind these quantitative statistics and other potentially unanticipated experiences of the project. Following on from this, a Focus Group was held to further explore the insightful commentary shared through the questionnaire. Eight open questions were prepared and shared with students in advance of the Focus Group to generate discussion.

\subsection{Recruitment}

The project was integrated as part of the provision for a twenty-credit undergraduate Academic Skills module. All students enrolled on this module $(n=21)$ had the opportunity to engage with the teaching, online platform and research. Accessible information sheets and consent forms were provided (Questionnaire and Focus Group), following the British Dyslexia Association's 'Dyslexia Style Guide', and the research was communicated to students with clarity during the teaching. The students were also taught by the researcher and the influence of this dual role was carefully considered. Engagement with both the pedagogical and research elements of the project were voluntary.

\subsection{Sample}

It is noted that teaching intensive universities such as this tend to have increased numbers of disabled students due to widening access agendas. As such, $15.39 \%$ of the university's students were registered as disabled at the time of the study. ${ }^{1}$ The students in the sample were training to become Creative Arts Practitioners, and studied a range of theories around inclusive practice, Critical Disability Studies and arts-based subjects. There is anecdotal evidence of a relatively higher incidence of dyslexia in art students, however this evidence lacks empirical rigour.

The cohort was $95 \%$ female with ages ranging from 18 to 53 . While $100 \%$ of students had access to the teaching and research project, only $43 \%$ completed the Questionnaire and 38\% participated in the Focus Group. It is therefore important to reflect upon the relevance of the findings to the wider cohort, and to consider whether crucial voices, such as those of disabled students, were represented. The accessibility of the teaching and research was highly considered but could be further improved. It is also not known whether the same voices were present in both data collection points. No specialist provision was knowingly in place for disabled students during

\footnotetext{
${ }^{1}$ Many more students are likely in the process of pursuing this registration or not in receipt of an official diagnosis and thus not able to formally register as disabled students, according to the limited definition of disability recognised by this system. Therefore, the percentage of students experiencing disablement may be significantly higher.
} 
the study, in acknowledgement of the university systems used to denote this. ${ }^{2}$

\subsection{Data Analysis}

Descriptive statistics were generated from the questionnaire's quantitative data, as well as a brief Thematic Analysis of the qualitative commentary [21]. Focus Group audio-recordings were transcribed and anonymised, and Thematic Analysis was employed to explore emerging patterns, and to develop a deeper understanding of the group's experiences.

\section{Findings}

\subsection{Engagement with the Online Platform}

In terms of concrete engagement with the platform, $14 \%$ of students physically uploaded notes to the portal during the life of the project $(n=3)$. This included $10 \%$ of students uploading repeatedly $(n=2)$. Uploads were a diverse mix of formal, handwritten notes and colourful, visual notes drawn on a tablet. $83 \%$ of the portal remained completely uninhabited with all contributions contained within the first $17 \%$ of the module, despite continued discussion about the project throughout the module.

\subsection{Questionnaire}

The initial mixed-methods questionnaire presented insightful and unanticipated findings, both in terms of engagement with the online platform and students' perceptions of this project. Of those who completed the questionnaire $(n=9,43 \%$ of the cohort), only one student suggested they accessed the platform to view the uploads. Interestingly, this student noted that this was "out of curiosity" rather than a reliance on the content to be found, and unfortunately "there was nothing there" on the week they had chosen to access the platform. For the $87 \%$ who did not consult the content on the online platform, reasoning for this included three core themes:

- No need (“didn't need to", "happy with my own notes", "forgot"),

- Seeking but not finding ("couldn't find it"),

- Alternatives ("helped each other on WhatsApp", "focused on reading and lecture slides").

Open comments suggested students overwhelmingly thought the project was a positive idea ("good idea",

\footnotetext{
2 This comment relates to the lecturer not being in receipt of any Individual Support Plans (ISPs) which the Disability Service generates for students in receipt of specialist provision.
}

"should continue", "helpful", "useful tool"). There were some students who provided further reasoning for potential lack of engagement, including "feeling self-conscious", "another thing on a long list of things to do" as well as "timing for me at the beginning of the course not good". When asked for improvements or developments, some students felt the project "could be open to abuse", a theme further explored in the Focus Group. In addition, the idea of recognition for those contributing was raised, and a need for an awareness of supply and demand: "if it works, I will help". These initial evaluative comments informed the development of open questions for the subsequent Focus Group.

\subsection{Focus Group}

Open questions were asked to invite further feedback on the project and to provide opportunity for students to elaborate on their initial commentary in the Questionnaire. Through analysis of this fortyfive-minute Focus Group with 38\% of the cohort $(n=8)$, the following themes became apparent:

- Lack of confidence;

- Social learning;

- Learning styles and preferences;

- Who's responsibility? Who's voice?

Each theme will be discussed individually to explore its relevance to the wider discussion.

\subsection{Lack of Confidence}

A strong theme apparent in the contributions of all members of the focus group was a lack of confidence in their own notetaking ability. This had different meanings to different members, with some acknowledging their own learning differences as a reason not to share their notes with peers. An example came from a student stating:

"I'm very aware that I'm very dyslexic, and things that I write in my notes, it makes sense to me, but it's like short hand. And I feel, sometimes, I feel like if people were to read my notes, they'd be like 'oh my god, he's a bit dull isn't he?",

Another student noted "more fundamentally though, there is a massive assumption that what we've written is actually correct". Another concurred: "Just because I've written it down, it could be a load of tosh... they're not vetted". A final student confirmed: "They're not a factual representation of what actually happened". Students gave several examples of what they do write in their notes, with the words "personal" and "questions" coming up a 
lot. Others discussed doodling more creatively, and not always being able to read back their own notes but using them more as processing in the live ("if I don't understand them after, nobody else will!").

Interestingly, another student spoke of their lack of confidence in relation to receiving support, noting “either I don't feel like I'm worthy of helping, or someone's more in need of help than I am, so I'm going to stay back."

\subsection{Social Learning}

This theme emerged in a number of ways. The first was in relation to the group's decision to use WhatsApp over the static Sharepoint platform created. Students commented that they had chosen to use WhatsApp to share their notes since it was "less formal", "quicker", "faster", "more open", "more connected to your daily life", "easier to use" and "everyone would answer". They discussed that "if you put it out on a [WhatsApp] group chat, everyone would answer and then someone would private message you too", whereas with the Sharepoint site "I had no way of knowing if it was useful to anyone, and therefore thought why am I wasting my time?" The immediate, discursive reinforcement provided through the WhatsApp platform appeared to motivate and sustain students' contributions over time. Whereas the initial diligence in uploading to the Sharepoint site soon dwindled without the recognition that the content was being accessed or understood ("I was a bit like 'I don't know if anyone's going to look at this", "Do you know if anyone did go on [Sharepoint] to look at them and learn from them?", "If I knew people were looking at it I would have carried on doing it"). Students also appeared concerned with the number of contributions or perspectives available, stating with WhatsApp: "having the views of, like, three of my peers... I can connect all the dots together", whereas with Sharepoint: "when I did upload it was only me and maybe one other person, so I thought, whoever's looking at this isn't getting a well-rounded view, so I stopped". The potential audience and confirmed presence of participants appeared significant for participation. Students insightfully described the Sharepoint site as "like, 2D", whereas they saw WhatsApp as an option for "richness" and "comradery".

Some students in the Focus Groups saw the entire experience as quite social, in asking for resources, guidance or support from their peers, and providing ideas themselves at other times. One student stated "I think the word is reciprocity; it's reciprocated. What we put on, we get back. If you contribute towards that, you get the help and support back". There is an emphasis here that students should have to be able to upload and contribute in order to be able to benefit from reading and accessing, which perhaps suggests a misunderstanding of the diversity of engagement and processing in undergraduate students.

\subsection{Learning Styles and Preferences}

Participants discussed the ways in which they learn effectively and referenced a number of strategies which didn't relate to notetaking. For example, one student noted: "I learn better to go away and read things myself rather than write things at the time". Another agreed, "I would go on to the readings then I would make notes from the readings". For another student: "I used to always turn up with a printout of the lecture notes and then write my comments on that particular slide. And then that's always in my file." This reflected an assumption that notetaking would be a necessary or valuable skill and provides insight and trajectory for future projects to consider other forms of learning. ${ }^{3}$ Another perspective, is that in their first weeks of undergraduate study and before completing their Academic Skills module, students perhaps didn't understand the method, value and merit of notetaking.

\subsection{Who's Responsibility? Who's Voice?}

The discussion returned on several occasions to the consideration of who notes were taken for, and why. This also highlighted a consideration of who's voices were represented in these comments and in this Focus Group. There were participants in the group who shared about their own experiences of dyslexia and who identified as disabled, but there was also confusion about the purpose and audience of the notes taken.

One student suggested "The responsibility again for us uploading something. It's kind of like 'why would I do that if I'm doing ok?". There was discussion around the students' responsibility for their learning, with one student suggesting "I wouldn't be happy turning up, taking notes and then passing them on if somebody didn't want to turn up... why should I share my time and my notes with people who may not be willing to take responsibility for their own learning." Another student confirmed "my notes are for me", taking the responsibility for the notes but also the ownership. The same student suggested "whilst there are some people who genuinely would benefit from those notes, we deal with that ourselves on a one to one basis as peers". The wording is interesting here, and perhaps the suggestion that the lecturer has imposed the expectation to upload notes has taken the autonomy

\footnotetext{
${ }^{3}$ Since the completion of this project, lecture capture software has been implemented across this degree. This will offer an alternative platform for revisiting and processing lecture content and may replace the potential benefit of this project to some, but not all, students.
} 
away from the group to develop and provide their own mechanisms of peer support. While it is positive to note the suggestion that peer support was readily provided, the suggestion that "if you're going to be responsible, and you genuinely want to know [about the notes/lecture], come knock on the door - the door's open. But not in the absence of turning up", suggests that students do not have a clear understanding of some of the barriers disabled students may face in either attending or reaching out for support. One of the primary intentions of the project was to move away from a students' needs model to a students' rights model [22], thus establishing the expectation to upload notes to enable engagement with content as a right without having to request 'additional' support as a need.

The word "selfish" came up several times, initially apologetically ("maybe it was selfish...") but with increased openness over time ("I don't mind picking up on that point of saying selfish... because I would consider for who's needs and purposes is this for?"). No-one in the Focus Group identified that they would benefit from access to notes taken in the group. This may be evidence that this format of provision is in fact not so desirable or may speak of the dynamic in the group as well as the representation of those within the group. It is acknowledged that a Focus Group may not have felt like an accessible or inclusive forum for some students, although this was of course diligently explored as far as possible. Some students may have not felt able to speak up against the dominant voices in the group and some of the strong opinions shared here and more widely in the course. This was recognised by the students, noting "It's quite weird if you look at the WhatsApp group in terms of a venn diagram of participation, what you find is not dissimilar to what you have in class. So the much more introverted people who don't tend to come [to class, to the Focus Group], similarly tend not to comment so much on WhatsApp". While it is encouraging that this was noticed, it was not necessarily problematised by the students. Introduction to theories of ableism and privilege (Hehir, 2002; Kumari Cambell, 2009) later in the students' modules would actively challenge some of these perspectives, but this again poses a challenge to the need for this provision so early in the first term of study.

\section{Discussion}

\subsection{Enabling and Disabling Attitudes}

As noted by Beckett and Buckner [23], prejudice towards disabled people is "embedded within dominant culture and [has] become institutionalised" (p. 875). The perpetuation of disabling attitudes within the group, identifying individual responsibility for impairment and the notion of the deserving and undeserving student evidences the need for a "courageous teaching that confronts resistance, is not afraid to conflict, and leads to genuine communication and learning across difference" [24] (p. 539). As noted, inclusive practice is a central pillar of the curriculum [25] and concepts of ableism and privilege would be explored explicitly later in the students' modules. In contrast with previous research which has considered the relationship between disabled students and technology [10], this project identified a resistance from non-disabled and disabled students to enable their disabled peers' engagement with technology. This adds further complexity to the suggestion of a 'digital divide' and adds yet another dimension to Burgstahler's [26] statement that disabled students in $\mathrm{HE}$ are on the "wrong side of a second digital divide" (p. 420).

\subsection{Specialist Application of Generic Technology}

Seale et al. [10] discuss that disabled students may have the "wrong kind of digital capital" (p. 126) in that the skills they acquire from secondary education are often not aligned with the more specialist, assistive technology provided in Higher Education. This was part of the rationale for applying a generic use of technology in this specialist context, in order that specialist skills shouldn't be a barrier to engagement. It is interesting to note that the technology perceived by the researcher to be generic (hyperlinks through the Virtual Learning Environment to a Microsoft platform), were perceived as specialist and inaccessible by most students. This highlights the centrality of effective transition to $\mathrm{HE}$ and induction into many logistical elements before it is possible to fully engage with discipline and subject specific teaching. The students' attraction to WhatsApp as a familiar, accessible and functional platform for their learning perhaps reflects their lack of confidence and unfamiliarity with various dimensions of the Higher Education experience. Perhaps WhatsApp became a transitional object of sorts, providing comfort and consistency in a period of transition and challenge.

\section{Conclusion}

While this pilot research project targets one small, element of specialist provision for disabled students, it is hoped that this discussion has highlighted the shared responsibility between all stakeholders to develop an inclusive learning environment. As QAA [7] note, equitable educational opportunities will be achieved through "inclusive design wherever possible and by means of 
reasonable individual adjustments wherever necessary" (p. 1-2). This project was an attempt to develop the inclusivity of the digital, physical and philosophical learning environment by sharing the responsibility for notetaking and enabling each other's learning. This could form part of what WAG [5] term a "blended model consisting of inclusive learning, reasonable adjustments and DSAs."

While the Disabled Students' Allowance (DSA) system enables highly specialist and often expensive provision to become accessible to disabled students, often transforming their experience of $\mathrm{HE}$, this is only available to students who identify as disabled. This requires students to subscribe to the necessary medical endorsement of the DSA and the Equality Act's (2010) definitions of disability, often at significant financial cost. This project offers an enabling learning environment for those who may not be aware of a specific diagnosis, may not subscribe to a deficit-based interpretation of disability, or may not have sufficient presenting features to qualify for a particular medical diagnosis. This shifts the focus away from the medicalized gaze and the burden of responsibility of the self-advocacy model of student success [17] and offers a shared responsibility between educators and all students to develop a collaboratively negotiated accessible provision. Beckett [27] suggests that this element of nurturing and developing an inclusive learning environment is as crucial for developing an inclusive society as meeting the needs of disabled individuals. Further to this, a notion that developed from this study was the potential for a university education to nurture moral and responsible citizens, who contribute proactively to enabling their peers. Could this become a unique graduate attribute that we commit to working towards, inviting students to review, acknowledge and challenges their ableist assumptions and move towards anti-oppressive pedagogy [27].

Further, this project contests the WAG [5] suggestion that "the level of investment required to develop inclusive learning practices within Higher Education Providers is substantial", since this project was embedded within routine teaching and learning practice and required no specific investment, only a shift in outlook and responsibility. While the specific format of this research project didn't necessarily result in a sustainable and embedded provision, the idea of sharing responsibility for accessibility has been established with this cohort and the conversation has been ignited at a modular, course, faculty and university level through dissemination. It is hoped that the act of developing this research is a step towards increasing accessibility in $\mathrm{HE}$, since "disability requires social action and is the collective responsibility of society" [28] (p. 69).

\section{Acknowledgements}

With sincere thanks to Val Norris, Clare Kell, Scott Seldon and Sophie Meace for their time and feedback in reflecting upon this project. Thanks to the students who embarked upon this pedagogical project and gave their time to share their reflections as part of the research.

\section{References}

[1] Willetts, D. (2014), "Written Statement to the House of Commons, 7 April." In Commons Hansard, 579 (201314), cols. 1-2, [online], Available at https://www.gov.uk/government/speeches/higher-educatio n-student-support-changes-to-disabled-students-allowances -dsa ( $9^{\text {th }}$ August 2019).

[2] Lewthwaite, S. (2014), 'Government cuts to Disabled Students' Allowances must be resisted', Disability \& Society, 29(7), pp. $1159-1163$.

[3] Martin, N., Wray, M., James, A., Draffan, E. A., Krupa, J. and Turner, P. (2019), 'Implementing Inclusive Teaching and Learning in UK Higher Education Utilising Universal Design for Learning (UDL) as a Route to Excellence', Society for Research into Higher Education Project Report.

[4] Department for Education (2019), 'Evaluation of Disabled Students' Allowances (DSAs)' [Online], Available at https://www.gov.uk/government/publications/ evaluation-of-disabled-students-allowances-dsas (8th February 2019).

[5] Welsh Assembly Government (2017), 'A Review of the Disabled Students' Allowances (DSA)' [online], Available at https://gov.wales/review-disabled-studentsallowances-0 ( $9^{\text {th }}$ August 2019).

[6] Welsh Assembly Government (2013), 'The Social Model' [Online], Available at https://gov.wales/topics/people-and-communities/equalitydiversity/rightsequality/disability/socialmodel/?lang=en (19 ${ }^{\text {th }}$ February 2019).

[7] Quality Assurance Agency for Higher Education (QAA) (2018), The UK Quality Code for Higher Education: Part $B$ [online], Available at https://www.qaa.ac.uk/docs/qaa/quality-code/chapter-b3_learning-and-teaching.pdf?sfvrsn=3500f781_8 $\quad\left(20^{\text {th }}\right.$ December 2019).

[8] Bracken, S. and Novak, K. (Eds) (2019), Transforming Higher Education Through Universal Design for Learning: An International Perspective, Abingdon, Routledge.

[9] Fitzwater, K. (2017), 'Theory and Practice in Art \& Design Education and Dyslexia: The Emancipatory Potentials of a Neurodiversity Framework', Journal of Philosophical Studies, 11(33), pp. $121-143$. 
[10] Seale, J., Georgeson, J., Mamas, C. and Swain, J. (2015), 'Not the Right Kind of 'Digital Capital'? An Examination of the Complex relationship Between Disabled Students, Their Technologies and Higher Education Institutions', Computers \& Education, 82, pp. $118-128$.

[11] Barnes, C. (2020), 'Understanding the Social Model of Disability: Past, Present and Future', In Watson, N., Roulstone, A. and Thomas, C. (Eds), Routledge Handbook of Disability Studies ( $2^{\text {nd }}$ Edn), London, Routledge, pp. 1229.

[12] Riddell, S. and Weedon, E. (2014), 'Disabled Students in Higher Education: Discourses of Disability and the Negotiation of Identity', International Journal of Educational Research, 63, pp. $38-46$.

[13] Hannam-Swain S. (2018), 'The Additional Labour of a Disabled PhD Student', Disability \& Society, 33(1), pp. $138-142$.

[14] Dolmage, J. T. (2017), Academic Ableism: Disability and Higher Education, University of Michigan Press.

[15] Couzens, D., Poed, S., Kataoka, M., Brandon, A., Hartley, J. and Keen, D. (2015), 'Support for Students with Hidden Disabilities in Universities: A Case Study', International Journal of Disability, Development and Education, 62(1), pp. $24-41$.

[16] Lawson, A. (2008), Disability and Equality Law in Britain, Oxford, Oregon, Hart Publishing.

[17] Osborne, T. (2019), 'Not Lazy, Not Faking It: Teaching and Learning Experiences of University Students with Disabilities', Disability \& Society, 34(2), pp. 228 252.

[18] Hutcheon, E. J. and Wolbring, G. (2012), 'Voices of "Disabled" Post-Secondary Students: Examining Higher Education "Disability" Policy Using an Ableism Lens', Journal of Diversity in Higher Education, 5(1), pp. 39-49.

[19] Roberts, P. and Hou, E. (2016), 'The Best Education Money Can Buy? Disabled University Students and the Equality Act 2010', International Journal of Discrimination and the Law, 16(2-3), pp. $143-160$.

[20] Hammer, S., Werth, S., and Dunn, P. (2009), 'Tertiary students with a disability or chronic illness: stigma and study', Paper Presented at Enabling Pathways: 3rd National Conference of Enabling Educators, 25-27th November 2009, Toowoomba, Australia, Retrieved from eprints.usq.edu.au/6278/1/Hammer_Werth_Dunn_AV.pdf (20 $0^{\text {th }}$ December 2019).

[21] Braun, V. and Clarke, V. (2006), 'Using thematic analysis in psychology', Qualitative Research in Psychology, 3, pp. 77-101.

[22] Beauchamp-Pryor, K. (2013), Disabled Students in Welsh Higher Education: A Framework for Equality and Inclusion, Rotterdam, Sense Publishers.
[23] Beckett, A. E. and Buckner, L. (2012), 'Promoting positive attitudes towards disabled people: definition of, rationale and prospects for anti-disablist education', British Journal of Sociology of Education, 33(6), pp. 873 - 891.

[24] Keith, N. (2010), 'Getting Beyond Anaemic Love: From the Pedagogy of Cordial Relations to a Pedagogy for Difference', Journal of Curriculum Studies, 42(4), pp. 539 -572 .

[25] Baglieri, S. and Shapiro, A. (2017), Disability Studies and the Inclusive Classroom ( $\left.2^{\text {nd }} E d n\right)$, New York, Oxon, Routledge.

[26] Burgstahler, S. (2002), 'Distance learning: universal design, universal access', Educational Technology Review, $10(1)$, pp. 420.

[27] Beckett, A. E. (2015), 'Anti-Oppressive Pedagogy and Disability: Possibilities and Challenges', Scandinavian Journal of Disability Research, 17(1), pp. 76-94.

[28] Steyaert, J. (2005), "Web Based Higher Education, The Inclusion/Exclusion Paradox", Journal of Technology in Human Services, 23(1/2), pp. 67 - 78. 